\title{
Research Paper: Evaluation of Parent-Child Interaction Therapy on Anxiety Level in Pre-Elementary School Children: A Randomized Controlled Trial
}

Bijan Pirnia $^{1^{*}}$, Elaheh Najafi ${ }^{2}$, Amir Lashkari ${ }^{3}$, Gelareh Saber Majidi $^{4}$

1. Department of Psychology, Faculty of Humanities, University of Science and Culture, Tehran, Iran.

2. Department of Psychology, Faculty of Humanities, Arak Branch, Islamic Azad University, Arak, Iran.

3. Department of Psychology, Faculty of Psychology and Social Sciences, Roudehen Branch, Islamic Azad University, Tehran, Iran.

4. Department of Psychology, South Tehran Branch, Payame Noor University, Tehran, Iran.

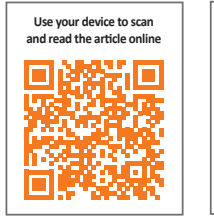

Crtation: Pirnia, B., Najafi, E., Lashkari, A., \& Saber Majidi, G. Evaluation of Parent-Child Interaction Therapy on Anxiety Level in Pre-Elementary School Children: A Randomized Controlled Trial. Journal of Practice in Clinical Psychology, 5(3), 167-176. https://doi.org/10.18869/acadpub.jpcp.5.3.167

Article info:

Received: 10 Jan. 2017

Accepted: 02 Jun. 2017

https://doi.org/10.18869/acadpub.jpcp.5.3.167

\section{Keywords:}

Parent-Child Interaction Therapy, Childhood anxiety, Addiction, Methadone maintenance treatment, Mother's anxiety

\begin{abstract}
Objective: Anxiety is one of the most common disorders of childhood. The treatment Interaction therapy can be used for determining anxiety symptomsis . In line with this, the Parent-Child Interaction Therapy (PCIT) has been successful in America as well as in some other countries. However, the application of this approach was more limited in Asia. The present study aimed at evaluating the extent of the effect of PCIT approach on child's anxiety level according to mother's anxiety index.

Methods: This randomized controlled trial was conducted at Bijan Center for Substance Abuse Treatment in Tehran, Iran, from December 1, 2013 to November 1, 2014. It involved parents referred to two addiction clinics for methadone maintenance treatment in regions of 7 and 9 in Tehran. A sample of 72 mothers and children (aged between 19 and 41 years with an average age of 29.4 years) were selected by convenient sampling method. According to the assumed cutting point score in anxiety index (response rate $=94 \%$ ), the subjects were assigned to two groups, i.e., control and experimental. Based on the three levels of mother's anxiety, i.e., low, medium, and high levels (response rate $=91 \%$ ), the subjects were sub-divided into six groups. PCIT protocol was presented to experimental groups during the six weekly sessions. A pretest and a posttest (after 12 weeks of training) were administered to the participants. The analysis of data was done by two-way factorial variance analysis test (ANOVA), Scheffe Post-hoc test, and Chi-square using IBM SPSS Statistics Version 20 (IBM Corp., Armonk, NY, USA).
\end{abstract}

Results: The results showed that PCIT has been effective in reducing the anxiety among children whose mothers had low anxiety level $(\mathrm{P}<0.001)$ while it was not effective in reducing the anxiety symptoms in children whose mothers had medium and high anxiety levels $(\mathrm{P}>0.05)$. Confidence interval of scores of children's anxiety in the group of mothers with low anxiety was $95 \%$, which was estimated to be 6.94(3.68-10.19) in experimental group and 12.91 (9.59-16.22) in control group.

Conclusion: Implications of these protocols are discussed with regard to their unique potential to address the clinical needs of young children with internalizing problems. However, further research into the evaluation of PCIT using a randomized controlled trial is recommendable.

\footnotetext{
* Corresponding Author: Bijan Pirnia, PhD Student Address: Department of Psychology, Faculty of Humanities, University of Science and Culture, Tehran, Iran. Tel: +98 (912) 5336780

E-mail: b.pirnia@usc.ac.ir
} 


\section{Introduction}

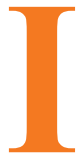

$\mathrm{n}$ recent years, there has been a high reflection upon childhood disorders among experts and parents. The premature beginning of childhood disorders is associated with more resistant periods against treatment and weaker treatment results with the passage of time (Ramsawh, Weisberg, Dyck, Stout, \& Keller, 2011; Luby, Si, Belden, Tandon, \& Spitznagel, 2009). Anxiety disorders are among the most common psychological disorders in childhood and have high similarity with other psychological disorders with regard to their common underlying mechanisms, usually associated with pervasive problems in life (Beesdo, Knappe, \& Pine, 2009; Rapee, Schniering, \& Hudson, 2009). On the other hand, syndrome of anxiety is common among parent users, especially in early abstinence (Pirnia, Givi, Roshan, Pirnia, \& Soleimani, 2016).

Anxiety is a common and undeniable phenomenon in human beings, which affects the performance (Ghahvechi-Hosseini, Fathi Ashtiani, \& Satkin, 2015). According to estimations, anxiety disorders have affected $9 \%$ of pre-elementary school children (Wichstrom et al., 2011). The changing nature of these symptoms has led to an increased rate of these disorders with the passage of time. Twenty- five percent of adolescents suffer from anxiety disorder, and $10 \%$ of them complain about a temperamental disorder during the last year (Kessler, Petukhova, Sampson, Zaslavsky, \& Wittchen, 2012). Anxiety is seen to be a more prevalent disorder than depression in OCD patients (Alizadeh Goradel, Pouresmali, Mowlaie, \& Sadeghi Movahed, 2016). Such anxiety disorder in preelementary school children can lead to depression and interactional disobedience disorders (Dougherty et al., 2013; Birmaher et al., 2009; Lavigne, LeBailly, Hopkins, Gouze, \& Binns, 2009; Lavigne et al., 1996). Not treating anxiety and depression symptoms will cause family function disorder, increaseding school absenteeism, problem in educational performance, and disrupted social relation during adulthood (Hopkins, Lavigne, Gouze, LeBailly, \& Bryant, 2013; Katz, Conway, Hammen, Brennan, \& Najman, 2011). On the other hand, deep consideration of family background of children shows that anxiety symptoms exist in one of the family members, especially parents and often the mother in the family, in addition to the child. Family studies and genetics represent increased risk of susceptibility to anxiety in children of parents affected with anxiety and depression disorders (Beesdo et al., 2009).

Intergeneration transmission of risk factors may reflect genetic factors, especially anxiety and depression in parents, which has developed in form of nurturing factors and has revealed control and extreme ignorance of children and limited competition feeling among them and encourages anxious and avoidance behavior (Goodman \& Gotlib, 1999, Wood, McLeod, Sigman, Hwang, $\&$ Chu, 2003). Research studies also support family tension of anxiety disorders (Beesdo et al., 2009; Rapee et al., 2009). Pre-elementary school children with anxiety disorders probably have mothers with anxiety disorders while no meaningful relationship was observed between children's anxiety disorders and fathers' anxiety disorders. Most of the studies rely on the role of parent-child interactions and child-rearing styles. Controlling social factors, such as limitation of entrance to kindergarten and exposure to challenging social conditions, help to solve child anxiety (McLeod, Wood, \& Weisz, 2007; Van Der Bruggen, Stams, \& Bögels, 2008). One of the important factors focused on treating of children is improving parent-child relationship. To this aim, levels of conflict between the parent and child have decreased and their interaction process and problem-solving skills have facilitated. A previous study has shown that positive interaction patterns such as active listening, eye contact, empathy, confirming and summarizing instead of criticizing and avoidance of cutting speech of others can be helpful in improving parent-child interaction (Stallard, 2005).

The Parent-Child Interaction Therapy (PCIT) was primarily developed by Sheila Eyberg in the early 1970s thatand is based on social learning theory and attachment theory. PCIT is an evidence-based treatment for young children with behavioral and emotional disorders that place emphasis on improving the quality of the parentchild relationship and changing parent-child interaction patterns (Brestan \& Eyberg, 1998). Federal and State policymakers recognize PCIT as a successful and effective evidence-based practice. In the early 1990s, the UC Davis CAARE Center began providing PCIT services to children and families. The treatment is given to children aged between 2 and 8 years with destructive behavior background. This therapy was first developed and conducted with the aim of filling the treatment gap in children psychological hygiene services in different age groups (Gurwitch et al., 2015). PCIT has been successfully used in America and some other countries due to its cost-effective approach, but its application is limited in Asia (Chen \& Fortson, 2015).

The theoretical foundation of this approach is based on the belief that since little children lack enough cognitive potentialities to change problematic behaviors, interaction therapy instead of direct involvement of children with problems focuses on changing of environmental 
context and PCIT. Clinical experiments express that interaction therapy is concomitant with a significant improvement of children's destructive behaviors and parents' anxiety and leads to an increase in parents' confidence in their children's control of extreme behaviors (Abrahamse et al., 2012; Hood \& Eyberg, 2003; Nixon, Sweeney, Erickson, \& Touyz, 2003; Nixon, Sweeney, Erickson, \& Touyz, 2004; Schuhmann, Foote, Eyberg, Boggs, \& Algina, 1998). In two studies (Choate, Pincus, Eyberg, \& Barlow, 2005), PCIT has been successfully used in decreasing separate anxiety symptoms. Moreover, in two other studies (Luby, Lenze, \& Tillman, 2011; Lenze, Pautsch, \& Luby, 2010), interaction therapy has been used with the aim of decreasing depression symptoms that contained hopeful results. A mental challenge that has attracted the minds of child psychotherapists for a while is the existence of double vision for specifying etiological aspects of anxiety disorders.

Both aspects of children's cognition and parent-child interaction specify anxiety symptoms in children to some extent. Cognitive psychotherapists take inefficient cognitions as reasons of respective symptoms while proponents of interaction approach target their criticism of cognitive treatments of pre-elementary school children on cognitive inabilities in benefiting from such treatments. This is because the inefficiency of medications is not clear about anxiety disorders (Wagner, 2003), and most parents avoid giving drugs to their children because of their side effects. Unfortunately, children with internalizing disorders are at a higher risk of exhibiting maladaptive emotional, social and behavioral difficulties that impede their ability to function productively within the social and academic settings at school.

The clinical evidences regarding the effectiveness of mother's psychological conditions on child's mood and cognitive structures in case of mutual interaction and the necessity of considering mother's mental potentiality in the process of treating anxiety in children needs to be considered. Also, the worth of understanding latent variables in planning efficient therapeutic processes should be taken into account. The aim of the present study was to examine the effectiveness of parent-child interactive treatment considering mothers' anxiety level. The findings of the present study can be effective in explaining the amount of effectiveness of child's treatment in a systematic framework and when affected by mother's psychological indices.

\section{Methods}

This randomized controlled trial was conducted at Bijan Center for Substance Abuse Treatment in Tehran,
Iran, from December 1, 2013 to November 1, 2014. The population of this study included all of the children whose parents were users of Methadone. The inclusion criteria included at least one of their parents referred to addiction quitting clinics in Tehran. From the respective community, 80 mothers were selected based on the knowledge of past studies and by voluntary sampling. Interaction therapy and data collection were done in two addiction centers in regions 7 and 9 in Tehran.

From the parents referred to the Bijan Center for Substance Abuse Treatment for methadone maintenance treatment in region of 7 in Tehran, a sample of 80 mothers and children were selected by convenient sampling method, screening and obtaining highest scores according to the assumed cut-off point score in anxiety index. After the beginning of research process, eight participants were removed from the research because of various reasons. Seventy- two participants were sub-divided into two groups, experimental and control groups. Based on the three anxiety levels of low, medium and high, the participants were assigned to six groups.

For 12-weeks, the mother-child interaction therapy was given to the experimental group with the aim of decreasing parents' anxious behaviors, and the three control groups were placed in a waiting list. Exclusion and inclusion criteria of research were precisely controlled. Inclusion criteria for children were: 1) Being in the age group of 5 to 7 years, and 2) Fulfilling DSM-IV diagnostic criteria for anxiety disorder. The exclusion criteria for mothers and children were: 1) Having IQ defects, and 2) Taking psychotherapeutic medicines of an equal unit doze for more than three months.

The research data were collected using clinical interviews and self-reported questionnaires. All of the interviews were digitally recorded, and the words were copied and codified. The main body of collected data was based on paper and pencil method. Therefore, at the beginning of the study and in the form of a baseline, Spence child anxiety questionnaire in the form of parent format was used. With the passage of two weeks from the end of treatment process, all the children were evaluated for the second time in the form of a posttest with the abovementioned questionnaire. The data were analyzed by two-way factorial variance analysis test (ANOVA) and Scheffe Post-hoc test. The entire process was carried out based on the latest version of the Declaration of Helsinki (Human, 2001). In this study, with regard to assumption of $\mathrm{Z}=1.645, \mathrm{~d}=0.2, \mathrm{a}=0.05$ and also power of test 1 $\beta=0.84$, the sample size was calculated to be 72 subjects. In this study, clinical structured interview, demographic 
researcher-made questionnaire, Spence children's anxiety scale and Beck anxiety inventory were used.

Clinical Structured Interview for Disorders (SCID): It is a clinical interview used for distinguishing axis-one disorders based on DSM-IV. The inter-rater reliability coefficient was reported to be 0.60 (First, Spitzer, Gibbon, \& Williams, 1995). The identification agreement of this instrument in the Persian language was useful for most of the special and general determinations with reliability of higher than 0.60 . Copa coefficient for all of the current determinations and determination of lifetime were 0.52 and 0.55 , respectively (Sharifi et al., 2009).

Demographic questionnaire: It is made by the researcher with the aim of applying and collecting individual information like age, education, marriage status, employment and the period of using drugs.

Spence Children's Anxiety Scale (SCAS): This scale was developed by Susan H. Spence in 1997 and is available in various languages. This scale is considered as one of the most effective instruments in evaluating different aspects of anxiety symptoms. It can evaluate the anxiety of pre-elementary school children. Parents' form of this scale has 38 statements in form of Likert scale of 0 (never) to 3 (always) with the highest score taken as 114 . This questionnaire has acceptable internal reliability as 0.89 (Nauta et al., 2004). Furthermore, the reliability and validity of Japanese version of this measure were reported appropriately (Ishikawa, Sato, \& Sasagawa, 2009). In Iran, previous studies (Mousavi, Moradi, Farzad, \& Mahdavi, 2007) have shown that the SCAS has suitable psychometric properties among the Iranian primary school children and it is a clinically valuable tool in the assessment of childhood anxiety. The Cronbach's alpha in this study was calculated for the internal reliability of the scale, and the internal consistency of the total score was 0.84 , which is consistent with the results reported by other investigators.

Beck anxiety inventory: Beck anxiety questionnaire is a self-reporting instrument for evaluating a range of anxiety symptoms and consist of 21 indices. Internal consistency for the BAI $=($ Cronbach's $\alpha=0.92)$ test-retest reliability (1 week) for the $\mathrm{BAI}=0.75$ (Beck, Epstein, Brown, \& Steer, 1988). The BAI was moderately correlated with the revised Hamilton Anxiety Rating Scale (0.51) and mildly correlated with the Hamilton Depression Rating Scale (0.25) (Beck et al., 1988). Investigation of psychometric features of respective questionnaire in Iranian community shows that the above questionnaire has high validity in comparative index of evalua- tors $(\mathrm{r}=72 \%)$, test retest reliability $(\mathrm{r}=83 \%)$, and internal reliability with Cronbach's $\alpha$ of $92 \%$ (Kaviani \& Mousavi, 2008).

\section{Results}

With regard to two independent variables of intervention therapy and parents' anxiety index, and dependent variable of child anxiety index with ordinal measure, parametric test of factorial variance analysis was applied (Reichardt, 2002). To this aim, essential assumptions of the respective test such as normal distribution, equality of variances and variance covariance matrix were investigated by Kolmogorov-Smirnov test, Leven test, and Box's M test, respectively. The necessary conditions for using two-way variance analysis were provided. For consequential investigations, Scheffe Post-hoc test was applied. The data were analyzed via IBM SPSS Statistics Version 20 (IBM Corp., Armonk, NY, USA). Our assumption was that lower levels of parent's anxiety had more positive effect on parent-child interaction therapy.

\section{Demographic features of the participants}

Table 1 shows the demographic status of the participants of the study; according to the results of the table, considering the most of the participants (experimental: 26, control: 21) had educational level of higher than Diploma. Regarding the age index, most of the participants belonged to older-than-25 years group (experimental: 20, control: 19). Distribution of participants in employment status index revealed that most of the participants were employed (experimental: 19, control: 25), and finally, most of the participants belonged to lower than 300 dollars monthly income (experimental: 23, control: 19). Data analysis using Chi-square test showed that the distribution of participants in case of demographic variables showed a significant difference in two indices including education level and monthly income (all $\mathrm{Ps}_{\mathrm{s}}<0.01$ ).

Table 2 represents the distribution of scores of children who participated in the study with respect to parent's anxiety levels. As it is evident, the highest variance between pretest and posttest scores of children belongs to mothers with low anxiety level in the experimental group.

In order to investigate the normality of distribution of the respective variable, Kolmogorov-Smirnov test was used. Respective statistics was equal to 0.716 , which represented the normality of distribution. Before using the multivariable parametric variance analysis test to ensure respective assumptions, Box and Leven's test were utilized. The Box's test was not meaningful for any of the 
Table 1. Demographic characteristics of the participants

\begin{tabular}{cccc}
\hline & Variable & Experiment & Control \\
\hline \multirow{2}{*}{ Education level } & Lower than diploma & $10(28 \%)$ & $15(42 \%)$ \\
Age & Higher than diploma & $26(72 \%)$ & $21(58 \%)$ \\
& $18-25$ & $16(44 \%)$ & $17(47 \%)$ \\
Employment status & Older than 25 & $20(56 \%)$ & $19(53 \%)$ \\
& Employed & $19(53 \%)$ & $25(69 \%)$ \\
Monthly income & Unemployed & $17(47 \%)$ & $11(31 \%)$ \\
& Less than 200 dollars & $23(64 \%)$ & $19(53 \%)$ \\
\hline
\end{tabular}

PRACTICE II
CINICAL PSYCH $\mathscr{L}$ LOGY

Table 2. The mean and standard deviation of scores of child anxiety with regard to mother's anxiety

\begin{tabular}{|c|c|c|c|c|c|c|c|c|c|c|c|}
\hline \multicolumn{6}{|c|}{ Experiment } & \multicolumn{6}{|c|}{ Control } \\
\hline \multicolumn{3}{|c|}{$\begin{array}{c}\text { Pretest } \\
\text { Mean(SD) }\end{array}$} & \multicolumn{3}{|c|}{$\begin{array}{c}\text { Posttest } \\
\text { Mean(SD) }\end{array}$} & \multicolumn{3}{|c|}{$\begin{array}{c}\text { Pretest } \\
\text { Mean(SD) }\end{array}$} & \multicolumn{3}{|c|}{$\begin{array}{c}\text { Posttest } \\
\text { Mean(SD) }\end{array}$} \\
\hline Low & Medium & High & Low & Medium & High & Low & Medium & High & Low & Medium & High \\
\hline $\begin{array}{l}12.71 \\
(1.87)\end{array}$ & $\begin{array}{l}13.13 \\
(2.01)\end{array}$ & $\begin{array}{l}14.37 \\
(1.93)\end{array}$ & $\begin{array}{c}6.94 \\
(1.66)\end{array}$ & $\begin{array}{l}11.27 \\
(2.12)\end{array}$ & $\begin{array}{l}10.75 \\
(1.82)\end{array}$ & $\begin{array}{l}13.01 \\
(2.12)\end{array}$ & $\begin{array}{l}12.94 \\
(2.23)\end{array}$ & $\begin{array}{l}13.79 \\
(2.24)\end{array}$ & $\begin{array}{l}12.91 \\
(1.69)\end{array}$ & $\begin{array}{l}12.61 \\
(2.01)\end{array}$ & $\begin{array}{l}13.19 \\
(1.97)\end{array}$ \\
\hline
\end{tabular}

PRACIICE In CLINICAL PSYCH LOGY

variables $(\mathrm{P}=1.01, \mathrm{~F}=5.11, \mathrm{M}$ Box=7.24). Moreover, the results of Lambdai Vilkez showed that effects of group are significant on combined variables of anxiety of mother and child (Lambdai Vilkez=0.19, $\mathrm{F}=18.90, \mathrm{P}<0.001$ ). Therefore, using of variance analysis test was possible.

The results of Table 3 showed that there is a significant difference between child anxiety scores in combination with mother's low anxiety $(\mathrm{F}=5.74)$ in experimental group in comparison with control group $(\mathrm{P}<0.001)$. In order to determine different aspects of this difference, Scheffe Post-hoc test was utilized. According to Table 4, the highest scores of children belonging to mothers with low anxiety level $(\mathrm{P}<0.001)$ has been presented.

\section{Discussion}

The results showed that interaction therapy could positively affect those children's anxiety whose parents had been lowly anxious while this treatment had no signifi-

Table 3. The results of variance analysis

\begin{tabular}{|c|c|c|c|c|c|c|}
\hline Group & Anxiety Levels & SS & df & MS & $\mathbf{F}$ & $\mathbf{P}$ \\
\hline & High & 711.15 & 5 & 142.23 & 2.64 & 0.08 \\
\hline \multirow[t]{3}{*}{ Experiment } & Medium & 587.70 & 5 & 1175.54 & 2.97 & 0.07 \\
\hline & Low & 623.10 & 5 & 124.62 & $5.74^{*}$ & 0.00 \\
\hline & High & 339.75 & 5 & 67.95 & 2.27 & 0.89 \\
\hline \multirow[t]{2}{*}{ Control } & Medium & 265.65 & 5 & 53.13 & 2.31 & 0.68 \\
\hline & Low & 153.09 & 5 & 51.03 & 2.35 & 0.59 \\
\hline
\end{tabular}


Table 4. Results of Scheffe test

\begin{tabular}{|c|c|c|c|c|c|}
\hline \multirow{2}{*}{ Variable } & \multirow{2}{*}{ Group } & \multicolumn{2}{|c|}{ Experiment } & \multicolumn{2}{|c|}{ Control } \\
\hline & & $(I-J)$ & $\mathbf{P}$ & $(1-J)$ & $\mathbf{P}$ \\
\hline \multirow{2}{*}{ High levels of anxiety } & Experimental & - & - & 2.64 & 0.08 \\
\hline & Control & 2.64 & 0.08 & - & - \\
\hline \multirow{2}{*}{ Medium levels of anxiety } & Experimental & - & - & 2.97 & 0.06 \\
\hline & Control & 2.97 & 0.06 & - & - \\
\hline \multirow{2}{*}{ Low levels of anxiety } & Experimental & - & - & $4.91^{*}$ & 0.01 \\
\hline & Control & $4.91 *$ & 0.01 & - & - \\
\hline
\end{tabular}

cant effect on those children's anxiety whose parents had been anxious in medium and high levels. This finding it is not in conflict with the current evidence base for PCIT. The effect of interaction therapy on anxiety symptoms has been determined by several studies in PubMed Database. In a study by Bjørseth and Vistrom (2016), children under the treatment of PCIT, compared to the children of control group, showed a significant reduction in behavioral problems after the treatment. Also, parents' parenting skills showed significant promotion compared to the control group. In a clinical trial, Webb, Thomas, McGregor, Avdagic and Zimmer-Gembeck (2016) examined the effectiveness of two kinds of Standard PCIT (S/PCIT), PCIT and motivation-enhanced PCIT (M/ PCIT), on the amount of internalizing and externalizing problems in pre-school students. Their results showed that both treatments were found to be significantly effective in reducing behavioral problems. In addition, a significant difference was not seen between the effectiveness of these two treatments.

Consistent with the results of the present study, another study by McFarlane, Burrell, Duggan, and Tandon (2016) showed that lower level of anxiety in mothers was associated with more favorable influence of cognitivebehavioral therapy. Puliafico, Comer and Pincus (2012) used interaction approach in treating children's anxiety disorders, and its results were representative of efficacy of respective treatment. In another study, PCIT has been successful in improving externally risky behaviors of children with delayed growth (Ros, Hernandez, Graziano, \& Bagner, 2016). This intervention had also been used for increasing the reliance on treatment process in Taipei families that contained hopeful results (Chen $\&$ Fortson, 2015). Moreover, there are some results in terms of efficacy of this treatment for depression disorder. Also, in the study by Lenze et al. (2010), interaction therapy was successfully applied so as to decrease the depression symptoms of pre-elementary school children.

As stated before, there is a belief that a relationship exists between parents' beliefs and expectations with their children anxiety disorders. In other words, parents' beliefs and expectations are reflected in their child nurturing behaviors. In this line, PCIT was applied to a sample of abused children in the United States with the aim of increasing their children's nurturing behaviors that represented the efficacy of this intervention (Batzer, Berg, Godinet, \& Stotzer, 2015).

Kortlander, Kendall and Panichelli-Mindel (1997) compared mothers having anxious children with mothers in the control group based on their expectations of their children in stressful conditions. Mothers of anxious children showed higher expectations, lower adaptive skills, and lower confidence in their management tasks. In this line, Shamir-Essakow, Ungerer and Rapee (2005) reported relation of anxiety symptoms of a sample of 104 pre-elementary school children that were selected based on high and low inhibitory behavioral index with mother anxiety and unsafe empathic style. There is a belief that high extent of parents' anxiety disorders is related to their over-control and negative behaviors (Bögels \& Brechman-Toussaint, 2006).

For explaining the relative findings of this study, we can refer to two important issues. First, the "levels of the anxiety of parents and child" is a synthetic factor considered to have a close interactive relationship with each other that invites the intervention systems to consider this significant index, which plays a significant part in foundation of systemic approaches. Secondly, from a perspective beyond just a simple interaction, the extent of parent's anxiety index in a regular cycle adjusts and 
facilitates child's anxiety levels. Conformity and congruence of behavioral problems between parent and child confirm this point. One thing that adds to the importance of findings of this study is the relationship between the extents of treatment response in child with different levels of parent's anxiety.

The findings of this study represented that children whose parent had low anxiety level had been significantly affected by the respective treatment while children whose parent had medium or high anxiety level did not experience significant changes going through the respective treatment. In confirming the study findings, the hypothesis that has attracted the attention of the writer of the article more than anything else is the defect in interaction and response system between the parent and child in highly anxious mothers. This condition evolved due to negative reinforcement approaches and is an index that is consequent with the treatment efficacy processes, which play a destructive role through interpersonal feedbacks. Since the child passes the growth process through an ethnomethodological realm, giving attention to mother's psychological factors in the process of treating symptoms of child is of high importance.

In line with macro education policy, the results of the present study indicate the need for a systemic and interactive look in reducing children's behavioral problems. In contrast with individual-centered therapeutic approaches, the findings of the present study seek the effective elements of treatment in the context of the family system. It is an approach that needs removing implementation limitations in spite of confirming the efficacy. In general, PCIT is well accepted among Iranian families and therapists, and the intervention was implemented in regular clinics in Iran without modifications to the core components of PCIT.

This study had several limitations. The most important limitations were as follows: 1) the cross-sectional nature of the study limits the overall conclusion and comprehensive forecast; and 2) use of a self-report assessment often creates a favorable social image and thus, selfreporting is associated with possible bias. It is recommended to obtain more reliable results. Hence, future researchers should conduct longitudinal studies on related issues so that the results can be compared with crosssectional studies and the differences provide the contexts for gaining new knowledge in the research methodology. Furthermore, to do more precise evaluations, using the neuropsychological instruments besides the questionnaire is recommended.

\section{Acknowledgments}

This research did not receive any specific grant from funding agencies in the public, commercial, or not-forprofit sectors. The authors are grateful to all those people who have participated in this study and helped in facilitating this research process. The author is particularly thankful to the management and personnel of Bijan Addiction Clinic.

\section{Conflict of Interest}

The author declared no conflicts of interest.

\section{References}

Abrahamse, M. E., Junger, M., Chavannes, E. L., Coelman, F. J. G., Boer, F., \& Lindauer, R. J. L. (2012). Parent-child interaction therapy for preschool children with disruptive behaviour problems in the Netherlands. Child and Adolescent Psychiatry and Mental Health , 6(1), 24. doi: 10.1186/1753-2000-6-24

Alizadeh Goradel, J., Pouresmali, A., Mowlaie, M., \& Sadeghi Movahed, F. (2016). The effects of transcranial direct current stimulation on obsession-compulsion, anxiety, and depression of a patient suffering from Obsessive-compulsive Disorder. Practice in Clinical Psychology, 4(2), 75-80. doi: 10.15412/j. jpcp.06040201.

Batzer, S., Berg, T., Godinet, M. T., \& Stotzer, R. L. (2015). Efficacy or chaos? Parent-child interaction therapy in maltreating populations: A review of research. Trauma, Violence, $\mathcal{E}$ Abuse. doi: $10.1177 / 1524838015620819$

Beck, A. T., Epstein, N., Brown, G., \& Steer, R. A. (1988). An inventory for measuring clinical anxiety: psychometric properties. Journal of consulting and clinical psychology, 56(6), 893. doi: 10.1037/0022-006x.56.6.893

Beesdo, K., Knappe, S., \& Pine, D. S. (2009). Anxiety and Anxiety Disorders in Children and Adolescents: Developmental Issues and Implications for DSM-V. Psychiatric Clinics of North America, 32(3), 483-524. doi: 10.1016/j.psc.2009.06.002

Birmaher, B., Ehmann, M., Axelson, D. A., Goldstein, B. I., Monk, K., Kalas, C., et al. (2009). Schedule for affective disorders and schizophrenia for school-age children (K-SADS-PL) for the assessment of preschool children - A preliminary psychometric study. Journal of Psychiatric Research, 43(7), 680-686. doi: 10.1016/j.jpsychires.2008.10.003

Bjørseth, A., \& Wichstrøm, L. (2016). Effectiveness of ParentChild Interaction Therapy (PCIT) in the treatment of young children's behavior problems. A randomized Controlled Study. PLOS ONE, 11(9), e0159845. doi: 10.1371/journal. pone.0159845

Bögels, S. M., \& Brechman-Toussaint, M. L. (2006). Family issues in child anxiety: Attachment, family functioning, parental rearing and beliefs. Clinical Psychology Review, 26(7), 834-856. doi: 10.1016/j.cpr.2005.08.001 
Brestan, E. V., \& Eyberg, S. M. (1998). Effective psychosocial treatments of conduct-disordered children and adolescents: 29 years, 82 studies, and 5,272 kids. Journal of clinical child psychology, 27(2), 180-189.

Chen, Y. C., \& Fortson, B. L. (2015). Predictors of treatment attrition and treatment length in parent-child Interaction therapy in Taiwanese families. Children and Youth Services Review, 59, 28-37. doi: 10.1016/j.childyouth.2015.10.009

Choate, M. L., Pincus, D. B., Eyberg, S. M., \& Barlow, D. H (2005). Parent-child interaction therapy for treatment of separation anxiety disorder in young children: A pilot study. Cognitive and Behavioral Practice, 12(1), 126-35. doi: 10.1016/ s1077-7229(05)80047-1

Dougherty, L. R., Tolep, M. R., Bufferd, S. J., Olino, T. M., Dyson, M., Traditi, J., et al. (2013). Preschool anxiety disorders: comprehensive assessment of clinical, demographic, temperamental, familial, and life stress correlates. Journal of Clinical Child \& Adolescent Psychology, 42(5), 577-589. doi 10.1080/15374416.2012.759225

First, M. B., Spitzer, R. L., Gibbon, M., \& Williams, J. B. W. (1995). The structured clinical interview for DSM-III-R Personality Disorders (SCID-II). Part I: Description. Journal of Personality Disorders, 9(2), 83-91. doi: 10.1521/pedi.1995.9.2.83

Ghahvechi Hosseini, F., Fathi Ashtiani, A., \& Satkin, M. (2015). Comparing Metacognitive Therapy with Cognitive Therapy on Reducing Test Anxiety and Meta-worry in Students. Practice in Clinical Psychology, 3(3), 203-218.

Goodman, S. H., \& Gotlib, I. H. (1999). Risk for psychopathology in the children of depressed mothers: A developmental model for understanding mechanisms of transmission. Psychological Review, 106(3), 458-90. doi: 10.1037/0033-295x.106.3.458

Gurwitch, R. H., Messer, E. P., Masse, J., Olafson, E., Boat, B. W., \& Putnam, F. W. (2015). Child-Adult Relationship Enhancement (CARE): An evidence-informed program for children with a history of trauma and other behavioral challenges. Child Abuse \& Neglect, 53, 138-45. doi: 10.1016/j.chiabu.2015.10.016

Hood KK, Eyberg SM. (2003). Outcomes of parent-child interaction therapy: Mothers' reports of maintenance three to six years after treatment. Journal of Clinical Child and Adolescent Psychology. 32(3), 419-29. doi: 10.1207/s15374424jccp3203_10

Hopkins, J., Lavigne, J. V., Gouze, K. R., LeBailly, S. A., \& Bryant, F. B. (2013). Multi-domain models of risk factors for depression and anxiety symptoms in preschoolers: Evidence for common and specific factors. Journal of Abnormal Child Psychology , 41(5), 705-22. doi: 10.1007/s10802-013-9723-2

Hossein Kaviani, H., \& Mousavi, A. S. (2008). [Psychometric properties of the Persian version of Beck Anxiety Inventory (BAI) (Persian)]. Tehran University Medical Journal. 66(2), 13640.

Human, D. (2001). Declaration of Helsinki. Lancet, 357(9251), 236. doi: 10.1016/s0140-6736(05)71342-8.

Ishikawa, S., Sato, H., \& Sasagawa, S. (2009). Anxiety disorder symptoms in Japanese children and adolescents. Journal of Anxiety Disorders, 23(1), 104-11. doi: 10.1016/j. janxdis.2008.04.003

Katz, S. J., Conway, C. C., Hammen, C. L., Brennan, P. A., \& Najman, J. M. (2011). Childhood Social Withdrawal, Interperson- al Impairment, and Young Adult Depression: A Mediational Model. Journal of Abnormal Child Psychology, 39(8), 1227-38. doi: 10.1007/s10802-011-9537-z

Kessler, R. C., Petukhova, M., Sampson, N. A., Zaslavsky, A. M., \& Wittchen, H. U. (2012). Twelve-month and lifetime prevalence and lifetime morbid risk of anxiety and mood disorders in the United States. International Journal of Methods in Psychiatric Research., 21(3), 169-84. doi: 10.1002/mpr.1359

Kortlander, E., Kendall, P. C., \& Panichelli-Mindel, S. M. (1997). Maternal expectations and attributions about coping in anxious children. Journal of Anxiety Disorders, 11(3), 297-315. doi: 10.1016/s0887-6185(97)00012-1

Lavigne, J. V., Gibbons, R. D., Christoffel, K. K., Arend, R., Rosenbaum, D., Binns, H., et al. (1996). Prevalence rates and correlates of psychiatric disorders among preschool children. Journal of the American Academy of Child E Adolescent Psychiatry, 35(2), 204-14. doi: 10.1097/00004583-199602000-00014

Lavigne, J. V., LeBailly, S. A., Hopkins, J., Gouze, K. R., \& Binns, H. J. (2009). The prevalence of ADHD, ODD, depression, and anxiety in a community sample of 4-year-olds. Journal of Clinical Child \& Adolescent Psychology, 38(3), 315-28. doi: $10.1080 / 15374410902851382$

Lenze, S. N., Pautsch, J., \& Luby, J. (2010). Parent-child interaction therapy emotion development: a novel treatment for depression in preschool children. Depression and Anxiety, 28(2), 153-159. doi: 10.1002/da.20770

Luby, J., Lenze, S., \& Tillman, R. (2011). A novel early intervention for preschool depression: findings from a pilot randomized controlled trial. Journal of Child Psychology and Psychiatry, 53(3), 313-22. doi: 10.1111/j.1469-7610.2011.02483.x

Luby, J. L., Si, X., Belden, A. C., Tandon, M., \& Spitznagel, E. (2009). Preschool depression. Archives of General Psychiatry, 66(8), 897-905. doi: 10.1001/archgenpsychiatry.2009.97

McFarlane, E., Burrell, L., Duggan, A., \& Tandon, D. (2016) Outcomes of a Randomized Trial of a Cognitive Behavioral Enhancement to Address Maternal Distress in Home Visited Mothers. Maternal and Child Health Journal, 21(3), 475-84 doi: 10.1007/s10995-016-2125-7

McLeod, B. D., Wood, J. J., \& Weisz, J. R. (2007). Examining the association between parenting and childhood anxiety: A meta-analysis. Clinical Psychology Review, 27(2), 155-72. doi: 10.1016/j.cpr.2006.09.002

Mousavi, R., Moradi, A. R., Farzad, V., \& Mahdavi, S. E. (2007) [Psychometric properties of the Spence children's anxiety scale with an Iranian sample (Persian)]. International Journal of Psychology, 1(1), 17-26.

Nauta, M. H., Scholing, A., Rapee, R. M., Abbott, M., Spence, S H., \& Waters, A. (2004). A parent-report measure of children's anxiety: psychometric properties and comparison with childreport in a clinic and normal sample. Behaviour Research and Therapy, 42(7), 813-39. doi: 10.1016/s0005-7967(03)00200-6

Nixon, R. D. V., Sweeney, L., Erickson, D. B., \& Touyz, S. W (2003). Parent-child interaction therapy: A comparison of standard and abbreviated treatments for oppositional defiant preschoolers. Journal of Consulting and Clinical Psychology, 71(2), 251-60. doi: 10.1037/0022-006x.71.2.251

Nixon, R. D. V., Sweeney, L., Erickson, D. B., \& Touyz, S. W. (2004). Parent-child interaction therapy: One- and two-year 
follow-up of standard and abbreviated treatments for oppositional preschoolers. Journal of Abnormal Child Psychology, 32(3), 263-71. doi: 10.1023/b:jacp.0000026140.60558.05

Puliafico, A. C., Comer, J. S., \& Pincus, D. B. (2012). Adapting Parent-child interaction therapy to treat anxiety disorders in young children. Child and Adolescent Psychiatric Clinics of North America, 21(3), 607-19. doi: 10.1016/j.chc.2012.05.005

Pirnia, B., Givi, F., Roshan, R., Pirnia, K., \& Soleimani, A. A (2016). The cortisol level and its relationship with depression, stress and anxiety indices in chronic methamphetamine-dependent patients and normal individuals undergoing inguinal hernia surgery. Medical Journal of The Islamic Republic of Iran, 30, 395. PMCID: PMC5004567

Ramsawh, H. J., Weisberg, R. B., Dyck, I., Stout, R., \& Keller, M. B. (2011). Age of onset, clinical characteristics, and 15-year course of anxiety disorders in a prospective, longitudinal, observational study. Journal of Affective Disorders, 132(1-2), 260-264. doi: 10.1016/j.jad.2011.01.006

Rapee, R. M., Schniering, C. A., \& Hudson, J. L. (2009). Anxiety disorders during childhood and adolescence: origins and treatment. Annual Review of Clinical Psychology, 5(1), 311-41. doi: 10.1146/annurev.clinpsy.032408.153628

Reichardt, C. S. (2002). Experimental and quasi-experimental designs for generalized causal inference. By William R. Shadish, Thomas D. Cook, and Donald T. Campbell. Boston Houghton Mifflin, 2002. Pp. 623. \$60.36 (paper). Social Service Review, 76(3), 510-14. doi: 10.1086/345281

Ros, R., Hernandez, J., Graziano, P. A., \& Bagner, D. M. (2016). Parent training for children with or at risk for developmental delay: the role of parental homework completion. Behavior Therapy, 47(1), 1-13. doi: 10.1016/j.beth.2015.08.004

Schuhmann, E. M., Foote, R. C., Eyberg, S. M., Boggs, S. R., \& Algina, J. (1998). Efficacy of parent-child interaction therapy: interim report of a randomized trial with short-term maintenance. Journal of Clinical Child Psychology, 27(1), 34-45. doi: 10.1207/s15374424jccp2701_4

Shamir-Essakow, G., Ungerer, J. A., \& Rapee, R. M. (2005). Attachment, behavioral inhibition, and anxiety in preschool children. Journal of Abnormal Child Psychology, 33(2), 131-143. doi: 10.1007/s10802-005-1822-2

Sharifi, V., Assadi, S. M., Mohammadi, M. R., Amini, H., Kaviani, H., Semnani, Y., et al. (2009). A Persian translation of the Structured Clinical Interview for Diagnostic and Statistical Manual of Mental Disorders, Fourth Edition: psychometric properties. Comprehensive Psychiatry, 50(1), 86-91. doi: 10.1016/j.comppsych.2008.04.004

Smith, K. E., \& Hudson, J. L. (2013). Metacognitive beliefs and processes in clinical anxiety in children. Journal of Clinical Child \& Adolescent Psychology, 42(5), 590-602. doi: $10.1080 / 15374416.2012 .755925$

Spence, S. H., \& Shortt, A. L. (2007). Research Review: Can we justify the widespread dissemination of universal, schoolbased interventions for the prevention of depression among children and adolescents? Journal of Child Psychology and Psychiatry, 48(6), 526-42. doi: 10.1111/j.1469-7610.2007.01738.x

Spence, S. H. (1997). Structure of anxiety symptoms among children: a confirmatory factor-analytic study. Journal of abnormal psychology, 106(2), 280-97. PMID: 9131848
Stallard P. (2005). A clinician's guide to think good-feel good: Using CBT with children and young people. New York: John Wiley \& Sons.

Stallard, P., Sayal, K., Phillips, R., Taylor, J. A., Spears, M., Anderson, R., et al. (2012). Classroom based cognitive behavioural therapy in reducing symptoms of depression in high risk adolescents: pragmatic cluster randomised controlled trial. BMJ, 345, 6058. doi: 10.1136/ bmj.e6058

Van der Bruggen, C. O., Stams, G. J. J. M., \& Bögels, S. M. (2008). Research review: The relation between child and parent anxiety and parental control: a meta-analytic review. Journal of Child Psychology and Psychiatry, 49(12), 1257-69. doi: 10.1111/j.1469-7610.2008.01898.x

Wagner, K. D. (2003). Efficacy of sertraline in the treatment of children and adolescents with major depressive disorder: two randomized controlled trials. JAMA, 290(8), 1033-48. doi: 10.1001/jama.290.8.1033

Webb, H. J., Thomas, R., McGregor, L., Avdagic, E., \& ZimmerGembeck, M. J. (2016). An evaluation of parent-child interaction therapy with and without motivational enhancement to reduce attrition. Journal of Clinical Child \& Adolescent Psychology, 46(4), 537-50. doi: 10.1080/15374416.2016.1247357

Wichstrøm, L., Berg-Nielsen, T. S., Angold, A., Egger, H. L., Solheim, E., \& Sveen, T. H. (2011). Prevalence of psychiatric disorders in preschoolers. Journal of Child Psychology and Psychiatry, 53(6), 695-705. doi: 10.1111/j.1469-7610.2011.02514.x

Wood, J. J., McLeod, B. D., Sigman, M., Hwang, W. C., \& Chu, B. C. (2003). Parenting and childhood anxiety: theory, empirical findings, and future directions. Journal of Child Psychology and Psychiatry, 44(1), 134-51. doi: 10.1111/1469-7610.00106 
